\title{
Fibre Volume Fraction and Impact Strength Analysis of Reinforced Polyester Composites
}

\author{
Dickson David Olodu** ${ }^{1 *}$, Osagie Ihenyen ${ }^{2}$ \\ 'Department of Mechanical Engineering, Faculty of Engineering, Benson Idahosa University, PMB 1100, Benin City, Edo State, Nigeria \\ ${ }^{2}$ Department of Production Engineering, Faculty of Engineering, University Benin, Benin City, Edo State, Nigeria
}

\begin{abstract}
Improper fibre volume analyses in most reinforced composites poses great challenges in polymer industries which results to the production of composites with low mechanical strength. This study investigates the fibre volume fraction and impact strength analysis of reinforced polyester composites. In this study, E-Glass fibres (hard and soft mat) were mixed with polyester at different composition by volume. The E-glass serves as reinforcement to the polyester, fourteen test specimens of the reinforced composites were developed with each of them having dimension of $210 \mathrm{~mm}$ length, $150 \mathrm{~mm}$ width and $50 \mathrm{~mm}$ thickness respectively. The properties of the developed reinforced composites such as volume fraction, impact energy, and impact strength were analysed from the values obtained from compact tension and Charpy impact test respectively. The results obtained shows that the effective thickness of the developed reinforced composites ranged from $60 \mathrm{~mm}$ to $100 \mathrm{~mm}$ at fibre fraction which ranges from 0.32 to 0.50 . The results obtained also shows that the specimens containing woven roving have greater resistance to fracture and impact damages due to high fibre volume fraction. Hence, the laminates impact strength is a function of its fibre volume fraction.
\end{abstract}

Keywords: E-glass fibre, Fibre Volume Fraction, Impact Strength, Reinforced Polyester Composites.

\section{INTRODUCTION}

Inadequate analysis of the production factors in composite production poses tremendous challenges. Fibre volume fraction and impact strength are major factors whose effects on composite such as reinforced polyester composites cannot be emphasised.

It has been observed that typical events such as cracking of coating, matrix, fibre exposure and breaks, and instantaneous fibre/matrix debonding in reinforced composite material are influencing conditions for which dominate crack growth, thereby posing a threat to the impact performance of these structures in service. Fracture events are often associated with finite increase in fracture area which leads to eventual catastrophic failure. These failures are imminently progressive due to the absence of sufficient and effective reinforcement, which prevent crack propagation through fibre bridging and crack arrest $[1,2]$.

Kao [3] examined toughness fracture of laminated composites, he observed that the energy required before fracture can take place is unexpectedly high, which is about five times larger than the separated Aluminium foil layer. Other investigations were also carried out to estimate the microstructure fracture mechanism which was applied to study the limited stability of fracture mechanism [4, 5]. Williams [6] in his analysis of the fracture mechanics of composites failure reviewed how fracture mechanism can be applied to the various fracture modes which was observed in composites. From his investigation, It was observed that the conventional methods may be used for short-fibre composites, he also observed that oriented laminates undergo delamination which is often parallel to the applied loads. In his study, energy release rate methods were used to analyse these failures. Pahizgar et al. [7] applied linear elastic fracture mechanics to study orthotropic materials. It was shown that the fracture toughness of unidirectional composites was independent of the crack length but dependent on crack-fibre orientation. To verify these claims, glass epoxy material was used. The fracture toughness for different crack-fibre orientations were obtained by utilising Solid Sap finite element program and compact tension specimens. Hence, an empirical formula relating to the fracture toughness of the material for different crack-fibre orientation was found. Mandel et al., [8] examined the micromechanical growth of crack in
* Corresponding author

Email: dolodu@biu.edu.ng
European Mechanical Science (2021), 5(1): 80-85

doi: https://doi.org/10.26701/ems.850970

Received: December 31, 2020

Accepted: March 8, 2020 
fibre reinforced materials using a 2-D, in their study; micromechanical finite element was used to investigate the stress conditions near the crack tip. The mechanical properties, interface between the fibres/matrix material and the geometry were considered. A close agreement between finite element and experimental values for the load required for the initiation of crack growth in the material were obtained. According to them, the arrest by the fibres showed that micromechanical finite element studies are applicable for the development of engineering models for fracture toughness of fibre reinforced material. It was also shown that the presence of high modulus fibres could significantly reduce the opening mode (mode-I) stresses in the matrix material near the crack tip and could result in crack arrest resulting to an increase in the effective fracture toughness. Further, it was noted that the shear stresses in the matrix material adjacent to the fibre and bond stresses between the fibre and matrix material are larger for a shear mode loading than for an opening mode loading. Although the stresses do not directly result crack growth, they were observed to cause fibre delamination which in turn could result in unstable crack growth. Garo and Trotman [9] used the concept of linear elastic fracture mechanics to study the effect of water and thickness on the fracture behaviour of fibre glass composite. It was found from their work that the stress intensity factor and fracture resistance decreased considerably due to the presence of water in such materials. Also, it was found that thickness has an effect of increasing the fracture resistance and stress intensity factor; hence, analytical relations for the $\mathrm{R}$-curves were presented to represent the behaviours of the material.

This research therefore focused on fibre volume fraction and impact strength analysis of reinforced polyester composites.

\section{MATERIALS AND METHODS}

\subsection{Materials}

Studies were carried out on samples fabricated by randomly varying plies of reinforcements in form of woven roving, hard and soft E-glass fibre mats, combined in unsaturated polyester resin (specific gravity 1.12 , viscosity of $65 \mathrm{cps}$ and gel time of $25 \mathrm{~min}$ ) matrix. The catalyst and accelerator used were methyl ethyl ketone peroxide (MEKP) and cobalt respectively due to their compatibility in polyester as curing agents at ambient temperature condition.

\subsection{Reinforced Polyester Composite Specimen Manufacture and Preparation}

The hand lay-up method was used for the production of 14 samples which consist of the randomly varied E-glass fibre reinforcement plies, neatly laid in an already prepared mould measuring $210 \mathrm{~mm} \times 150 \mathrm{~mm} \times 50 \mathrm{~mm}$. Hence, the reinforcement was impregnated with catalysed polyester resin, and allowed for a period of one month to completely cure at ambient condition. The samples for the tests were cut into 28 specimens, for which 14 samples were compact test (CT) specimens used for fracture mechanics test and the other 14 specimens were for impact tests respectively, using a hack saw cutting blade and tested in accordance with the ASTM and ISO standard for fracture mechanics and impact tests for composite materials respectively.

Table 1. The Table Below Shows the Variation Order in which Reinforcing Plies were Combined in the Specimen for the Fracture Mechanics and Impact Test Analyses.

\begin{tabular}{|c|c|c|c|c|}
\hline \multirow{2}{*}{$\begin{array}{l}\text { Material } \\
\text { Specimen }\end{array}$} & \multirow{2}{*}{ Reinforcement Composition } & \multicolumn{3}{|c|}{$\begin{array}{c}\text { Geometry of Samples in milli } \\
\text { metre }(\mathrm{mm})\end{array}$} \\
\hline & & $\begin{array}{l}\text { Length } \\
\text { (L) }\end{array}$ & $\begin{array}{l}\text { Width } \\
(\mathrm{W})\end{array}$ & $\begin{array}{c}\text { Thickness } \\
(\mathrm{t})\end{array}$ \\
\hline A & $\begin{array}{c}\text { One ply of soft mat } \\
\text { Two plies of woven roving } \\
\text { One ply of soft mat }\end{array}$ & 210 & 150 & 4.4 \\
\hline B & $\begin{array}{l}\text { One ply of woven roving } \\
\text { Two plies of soft mat } \\
\text { One ply of woven roving }\end{array}$ & 210 & 150 & 5.2 \\
\hline C & $\begin{array}{l}\text { One ply of }(42.7 \mathrm{~g}) \text { hard mat } \\
\text { Two plies of woven roving }\end{array}$ & 210 & 150 & 4.5 \\
\hline D. & $\begin{array}{l}\text { One ply of woven roving } \\
\text { Two plies of }(42.7 \mathrm{~g}) \text { hard mat } \\
\text { One ply of woven roving }\end{array}$ & 210 & 150 & 6.4 \\
\hline $\mathrm{E}$ & $\begin{array}{c}\text { One ply of soft mat } \\
\text { Two plies of }(42.7 \mathrm{~g}) \text { hard mat } \\
\text { One ply of soft mat }\end{array}$ & 210 & 150 & 7.1 \\
\hline $\mathrm{F}$ & $\begin{array}{l}\text { One ply of }(42.7 \mathrm{~g}) \text { hard mat } \\
\text { Two plies of soft mat } \\
\text { One ply of }(42.7 \mathrm{~g}) \text { hard mat }\end{array}$ & 210 & 150 & 5.7 \\
\hline G & Five plies of woven roving & 210 & 150 & 7.7 \\
\hline $\mathrm{H}$ & Twelve plies of soft mat & 210 & 150 & 8.4 \\
\hline 1 & Eight plies of $(42.7 \mathrm{~g})$ hard mat & 210 & 150 & 10.3 \\
\hline J & $\begin{array}{l}\text { One ply of soft mat } \\
\text { One ply of woven roving } \\
\text { One ply of soft mat }\end{array}$ & 210 & 150 & 6.8 \\
\hline $\mathrm{K}$ & $\begin{array}{l}\text { One ply of soft mat } \\
\text { Two plies of }(42.7 \mathrm{~g}) \text { hard mat } \\
\text { One ply of woven roving } \\
\text { Two plies of }(42.7 \mathrm{~g}) \text { hard mat } \\
\text { One ply of soft mat }\end{array}$ & 210 & 150 & 7.32 \\
\hline $\mathrm{L}$ & $\begin{array}{l}\text { Two plies of soft mat } \\
\text { Two plies of woven roving } \\
\text { Two plies of soft mat }\end{array}$ & 210 & 150 & 7.2 \\
\hline M & $\begin{array}{l}\text { Two plies of woven roving } \\
\text { Four plies of soft mat } \\
\text { Two plies of woven roving }\end{array}$ & 210 & 150 & 10.2 \\
\hline $\mathrm{N}$ & $\begin{array}{l}\text { Two plies of }(42.7 \mathrm{~g}) \text { hard mat } \\
\text { Four plies of soft mat } \\
\text { Two plies of woven roving }\end{array}$ & 210 & 150 & 13.5 \\
\hline
\end{tabular}

\subsection{Fracture Mechanics Assumptions in Reinforced Composite Analysis}

The following assumptions were made in this study;

i) Resin interlayer is isotropic and has uniform thickness.

ii) The plies or layers are perfectly bonded in the laminate everywhere except in the region where a flaw is initiated or present from the surface notched tip.

iii) There is perfect bonding between the resin and the fibre.

iv) The resin and the fibres are experiencing the same stress 
due to the applied impact force.

v) Crack tip have zero radius.

\subsection{Areal Weight $\left(A_{w}\right)$ and Fibre Volume Fraction $\left(V_{f}\right)$ Data Analysis}

Material thickness for a reinforced composite laminates are function of the amount of resin included in the composite. This illustrates the fibre volume fraction as a characteristic of its areal weight $\left(\mathrm{A}_{\mathrm{w}}\right)$. The areal weight is expressed in $g$ of $1 \mathrm{~m}^{2}$ of the reinforced mat; the areal weight depends on fibre density, bundle size, weave style and so on. Using the equation 1 , the fibre volume fraction, $V_{f}$ can be obtained if the fibre mass $m$, area, $A$, thickness of laminate, $B$ and numbers of plies, $n$ are known. Also, area weight, $A_{w}$ can be evaluated using equation 1 . This relationship between laminate thickness and fibre volume requires that the fibre density be known also before using Equation 1.

$$
V_{f}=\frac{n A_{w}}{\rho_{f} B}
$$

\subsection{The Charpy Impact Test}

The Charpy impact test was used to measure the energy absorption capacity of the reinforced polyester composite materials. A notched bar of reinforced composite specimen was supported as a simple beam so that the vertical faces are positioned away from the point of impact. The test specimens are trucked at the middle with a hammer which is incorporated on the test equipment. The impact test had a setup similar to the 3PB test and this is the most appropriate for the composite materials which damage and fracture in a brittle manner because of the presence of micro defect or a surface scratch; and the stress concentrated at these regions will accelerate the failure rate under sudden impact force. Moreover, the energy absorbed by the blow in machine was determined by a measuring device incorporated in the machine.

\subsection{Experimental Procedure for Impact Strength Determination}

Before the conduct of the Charpy impact test, the specimen geometry was marked out on the plate using the dimensions specified in the design. The specimens were cut, after which, the specimen was position on the anvil. The right position of the impactor (impact head) and the height of the pendulum were set. After securing the specimen, the pendulum was raised to position and allowed to freely swing towards the specimen to impact it to breaking, because the test was a destructive test similar to the fracture mechanics test.

In this study, the energy required to break test specimen was determined from the data recorded on the metering device on the machine. Furthermore, the impact energy for a composite material using fracture mechanics approach was obtained using Equation 2 [10, 11].

$$
U=\frac{E}{\phi b(d-c)}
$$

Where $\mathrm{U}=$ Impact Energy; E=Energy in $\mathrm{kJ} / \mathrm{m}^{2}$ or $\mathrm{ft} . \mathrm{lb} / \mathrm{in}^{2} \mathrm{re}-$ gistered in the test specimen; $\mathrm{b}=$ Specimen breadth; $\mathrm{d}=$ Specimen Depth; c and $\phi$ are calibration factors which depend on specimen, crack dimension and compliance [12].

\section{RESULTS AND DISCUSSIONS}

\subsection{Fibre Volume Fraction Analysis}

The fibre volume fraction of the reinforcement used in the laminate were obtained using Equation 1, the results were presented on Table $2 \mathrm{a}$ and $2 \mathrm{~b}$ respectively.

Table 2a. Reinforcement Volume Fraction Data Analysis

\begin{tabular}{|c|c|c|c|}
\hline Reinforcement & Woven Roving & Hard Mat & Soft Mat \\
\hline Mass, $\mathrm{m}(\mathrm{g})$ & 1000 & 1000 & 200 \\
\hline Area, $\mathrm{A}\left(\mathrm{m}^{2}\right)$ & 1.50 & 2.268 & 5.67 \\
\hline Fibre Density, $\rho_{\mathrm{f}}\left(\mathrm{g} / \mathrm{m}^{3}\right)$ & $1.11 \mathrm{E}+06$ & $1.10 \mathrm{E}+06$ & $1.76 \mathrm{E}+05$ \\
\hline Areal Weight, $\mathrm{A}_{\mathrm{w}}\left(\mathrm{g} / \mathrm{m}^{2}\right)$ & 666.67 & 440.92 & 35.27 \\
\hline
\end{tabular}

Table 2b. Reinforcement Volume Fraction Data Analysis

\begin{tabular}{|c|c|c|c|c|c|c|}
\hline $\begin{array}{c}\text { Speci- } \\
\text { men }\end{array}$ & $\begin{array}{c}\text { Woven } \\
\text { Roving }\end{array}$ & $\begin{array}{c}\text { Hard } \\
\text { Mat }\end{array}$ & Soft Mat & $\begin{array}{c}\text { No. of } \\
\text { Plies }\end{array}$ & $\begin{array}{c}\text { Thick- } \\
\text { ness, B } \\
(\mathrm{mm})\end{array}$ & $\begin{array}{c}\text { Volume } \\
\text { Fraction, } \\
\text { V }_{f}\end{array}$ \\
\hline A & 2 & 1 & 1 & 4 & 4.4 & 0.47 \\
\hline B & 1 & 2 & 1 & 4 & 5.2 & 0.35 \\
\hline C & 2 & 1 & Nil & 3 & 4.5 & 0.36 \\
\hline D & 2 & Nil & 2 & 4 & 6.4 & 0.34 \\
\hline E & Nil & 2 & 2 & 4 & 7.1 & 0.21 \\
\hline F & Nil & 2 & 2 & 4 & 5.7 & 0.21 \\
\hline G & 5 & Nil & Nil & 5 & 7.7 & 0.39 \\
\hline H & Nil & 12 & Nil & 12 & 8.4 & 0.57 \\
\hline I & Nil & Nil & 8 & 8 & 10.3 & 0.16 \\
\hline J & 1 & 1 & 1 & 3 & 6.8 & 0.21 \\
\hline K & 1 & 2 & 4 & 7 & 7.32 & 0.4 \\
\hline L & 2 & 2 & 2 & 6 & 7.2 & 0.41 \\
\hline M & 4 & 4 & Nil & 8 & 10.2 & 0.39 \\
\hline N & 2 & 4 & 2 & 8 & 13.5 & 0.27 \\
\hline
\end{tabular}

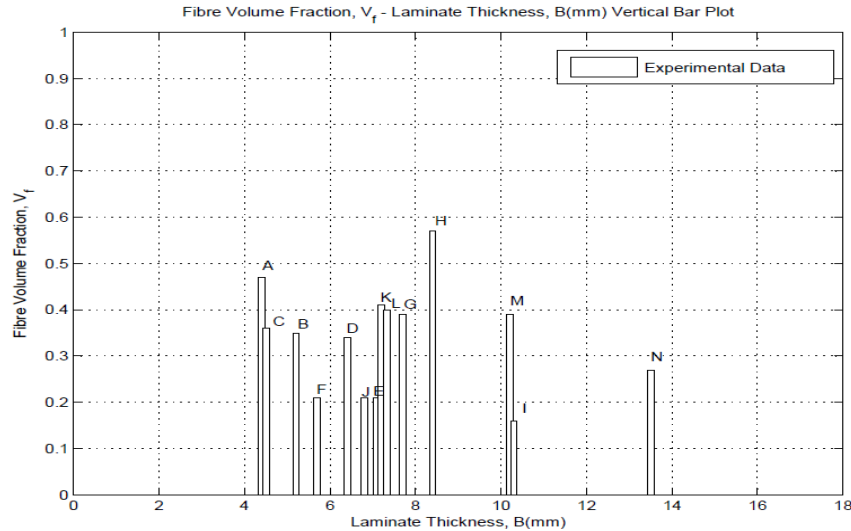

Figure 1. Bar Plot of Fibre Volume Fraction of Laminates against Test Specimen Thickness 


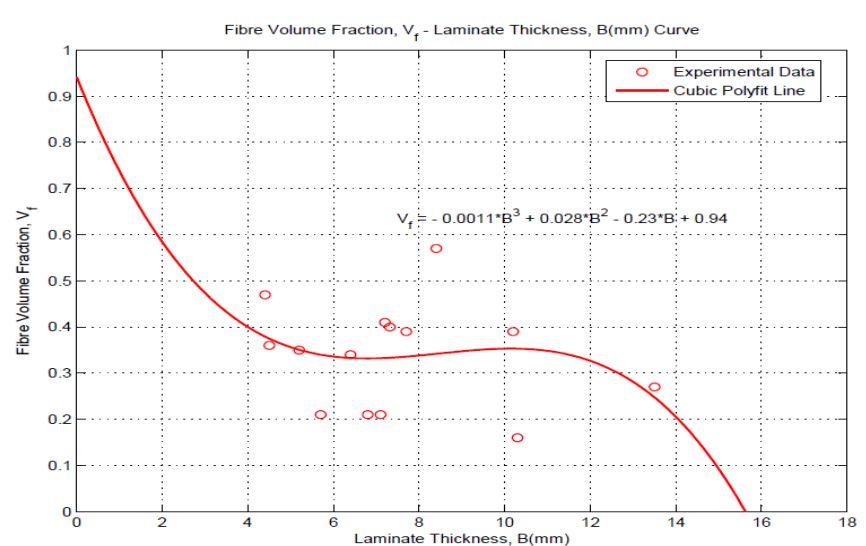

Figure 2. Graph of Fibre Volume Fraction of Laminates against Specimen Thickness Profile

Table 3. Impact Results for Specimens A to N using the Charpy Impact Test Machine

\begin{tabular}{|c|c|c|c|c|c|}
\hline $\begin{array}{c}\text { Composite } \\
\text { Samples }\end{array}$ & $\begin{array}{c}\text { Thickness } \\
\text {, B (mm) }\end{array}$ & No. of Plies & $\begin{array}{c}\text { Volume } \\
\text { Fraction, } \\
V_{f}\end{array}$ & $\begin{array}{c}\text { Impact } \\
\text { Energy, } \\
\text { E J) }\end{array}$ & $\begin{array}{c}\text { Impact } \\
\text { Strength, U } \\
\left(\mathrm{J} / \mathrm{mm}^{2}\right)\end{array}$ \\
\hline A & 4.4 & 4 & 0.47 & 87 & 6.2 \\
\hline B & 5.2 & 4 & 0.35 & 75 & 4.51 \\
\hline C & 4.5 & 3 & 0.36 & 72 & 5 \\
\hline D & 6.4 & 4 & 0.34 & 78 & 3.75 \\
\hline E & 7.1 & 4 & 0.21 & 84 & 3.7 \\
\hline F & 5.7 & 4 & 0.21 & 87 & 4.77 \\
\hline G & 7.7 & 5 & 0.39 & 108 & 4.38 \\
\hline H & 8.4 & 12 & 0.57 & 96 & 3.57 \\
\hline I & 10.3 & 8 & 0.16 & 39 & 1.18 \\
\hline J & 6.8 & 3 & 0.21 & 60 & 2.76 \\
\hline K & 7.32 & 7 & 0.4 & 72 & 3.07 \\
\hline L & 7.2 & 6 & 0.41 & 120 & 5.21 \\
\hline M & 10.2 & 8 & 0.39 & 155 & 4.75 \\
\hline N & 13.5 & 8 & 0.27 & 130 & 3.61 \\
\hline & & & & & \\
\hline
\end{tabular}

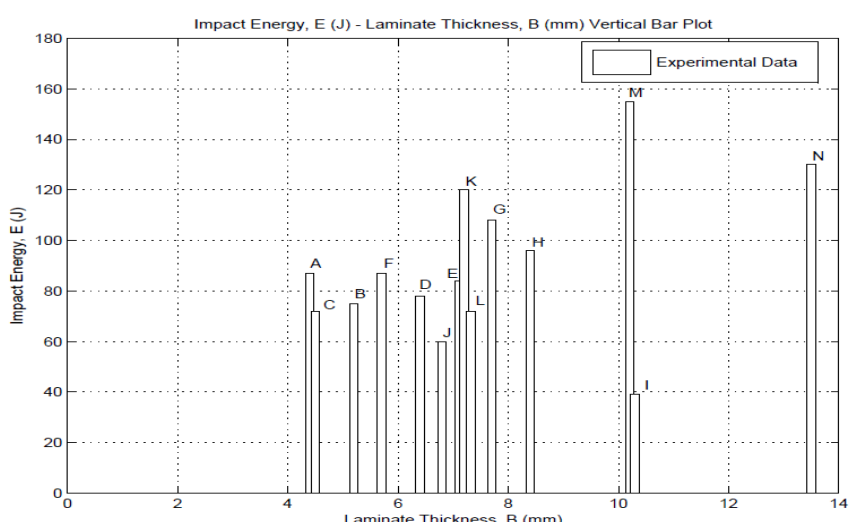

Figure 4. Bar Plot of Impact Energy of Laminates for Various Specimen Thicknesses
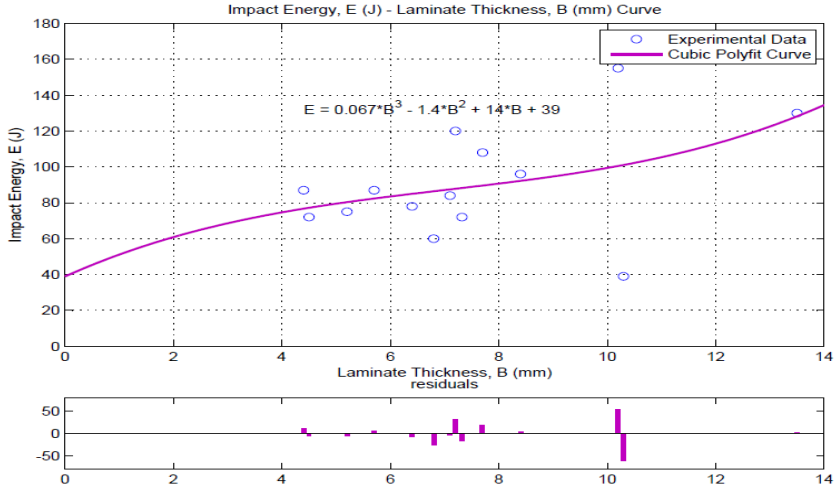

Figure 5. Impact Energy of Laminates versus Specimen Thicknesses Curve

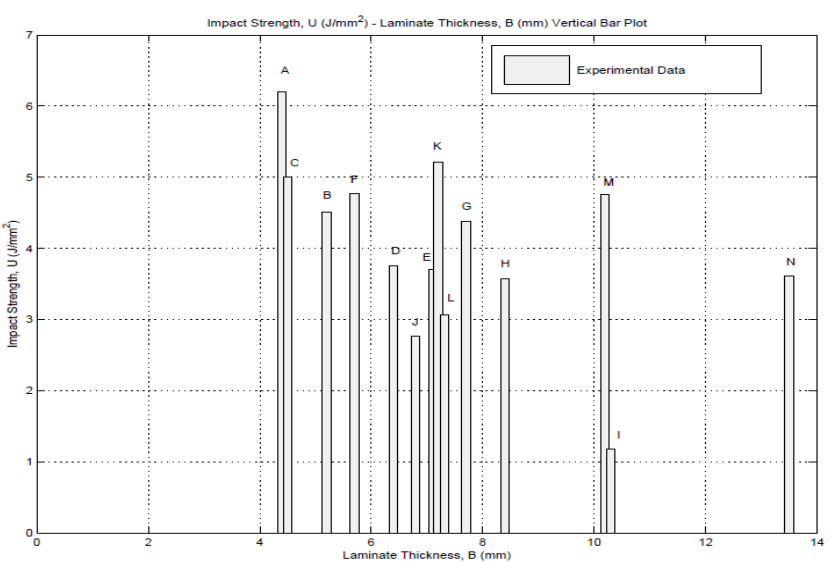

Figure 6. Bar Plot for Impact Strength of Laminates for Various Specimen Thicknesses

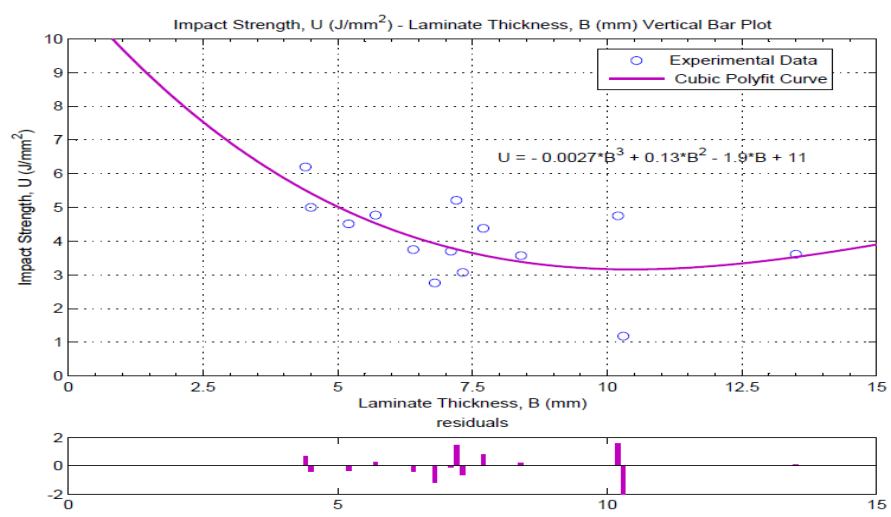

Figure 7. Impact Strength of Laminates versus Specimen Thicknesses Curve

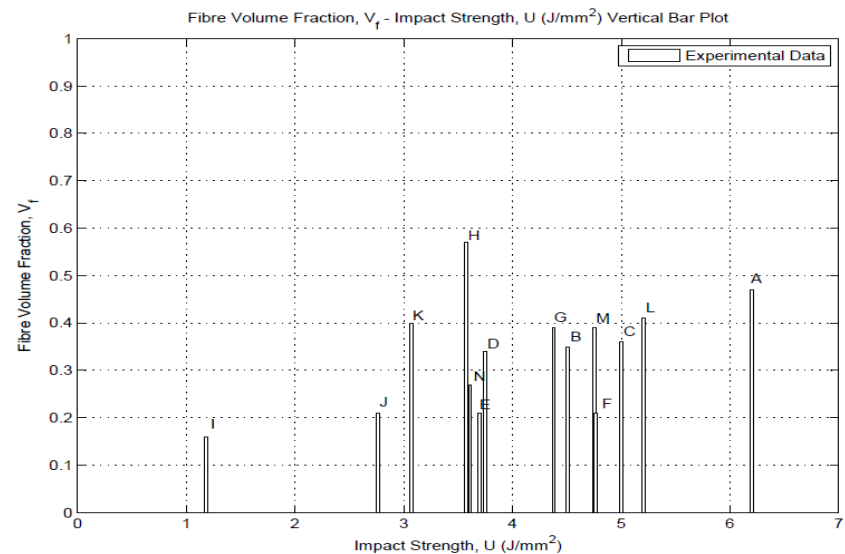

Figure 8. Bar Plot for Fibre Volume Fraction of Laminates versus Impact Strength 


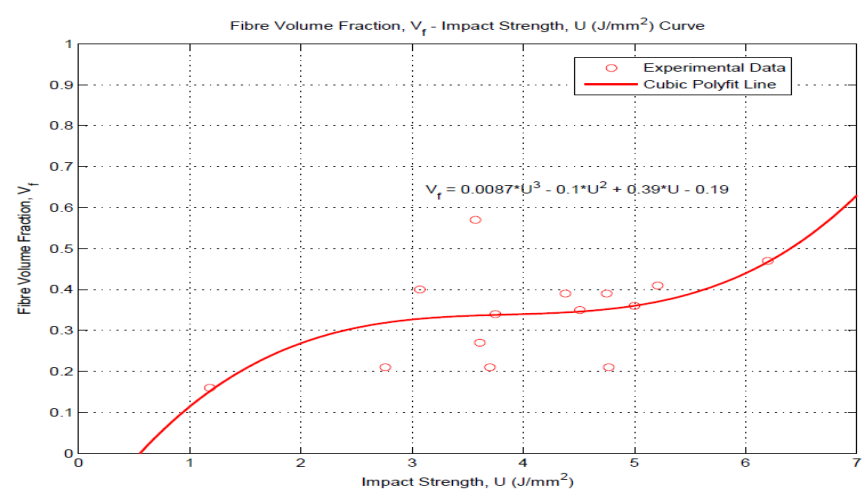

Figure 9: Fibre Volume Fraction of laminates versus impact strength curve

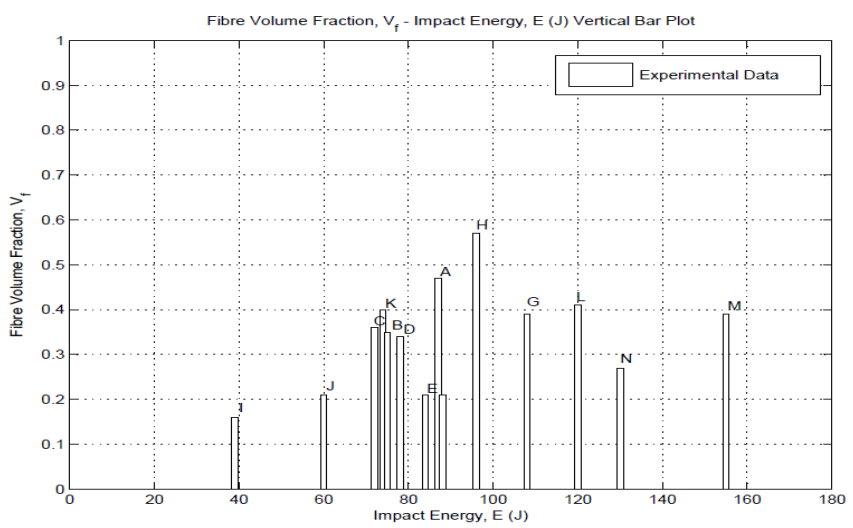

Figure 10: Bar Plot of Fibre Volume Fraction of Laminates Versus Impact Energy

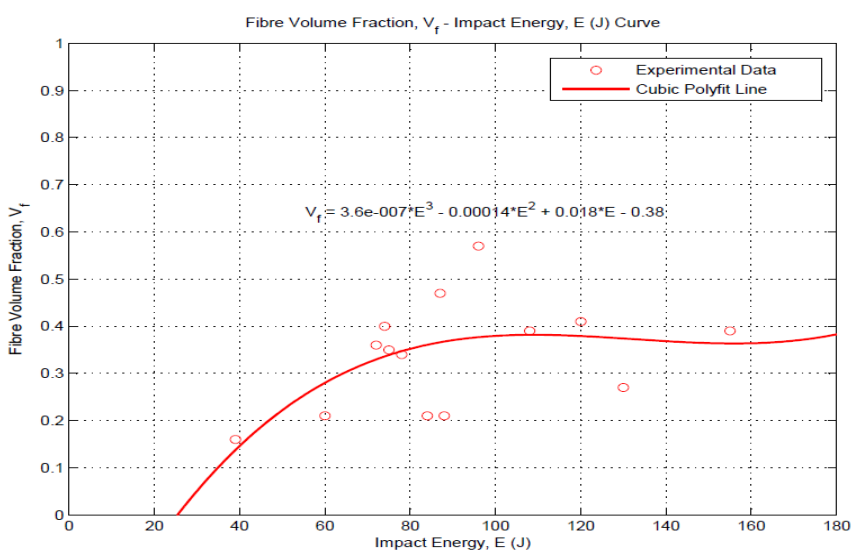

Figure 11: Fibre Volume Fraction of Laminates versus Impact Energy Curve

\subsection{Discussion of Results}

From the behaviour of the above bar plot and curve presented in figures 1 and 2 respectively, it was clear that as the fibre volume fraction is reduced, the thickness also shrinks which could be established that the fibre volume fraction determines the laminate thickness.

Using the Charpy impact machine, the impact strength was determined for the specimens containing varied volume fraction of reinforcements. It was observed that those specimens containing woven roving form of reinforcement had better impact resistance when compared with those that contained only soft and hard mat, irrespective of the volume fraction in which they were present. This was found to be as a result of the form, integrity, the virtue of the volume to compaction ratio, and their filament's length (Table 3). This observation was a testimony to the fact that for a composite structure to possess adequate impact properties, the fibre length should be considered and ensured it is sufficiently long enough to resist failure and ensure good performance. Hence, this will satisfy the purpose of the impact test to measure the toughness and energy absorption capacity of the material without failure under a single blow.

Figure 4 and 5 shows the experimental result curve for the impact energy versus specimen thickness, and from the curve, it was observed that the thickness and Glass fibre content plays a vital role in the impact strength of laminates with the exception of specimens E, L, J, I which were low in impact energy as a result of fibre composition. Hence, it can be said that the more the woven glass fabric percentage, the more the impact toughness. It was also observed that the impact energy increased significantly when the specimen thickness increased, this trend is true irrespective of laminate thickness, but depend on the fibre form and volume fraction. The maximum impact energy for specimen $\mathrm{M}$ is 155J. The level of increase in impact energy for each specimen depends on the fibre form rather than on fibre volume fraction. However, this is mainly due to increased number of load bearing fibres at the critical section compared to laminates which have low strength fibre composition. Moreover, the high impact energy in some test specimen such as specimen $M$ is due to increased thickness, high fibre volume fraction and increased number of plies. This simply means that proper combination of these factors; specimen thickness, fibre volume fraction and number of plies can affect the results of impact energy. This made the results obtained from this experiment different from past literatures.

Figure 6 shows that the impact strength of the specimens is not a function of the thickness as some specimens with greater thickness had low impact strength, but it was a function of the reinforcement combinations as those with woven roving mats performed better under sudden impact force. But from figure 7, the trend of the curve was observed to drop with increasing thickness, which further proved that the impact performance is dependent on reinforcement combinations of the glass fibre mats used for the manufacturing of the specimens.

From figures 8 and 9, it is shown clearly that the fibre volume fracture has a significant contribution to the impact performance of reinforced polyester composites when exposed to sudden impact load. The curve indicated an increase in impact strength as the fibre volume fraction rises.

From the data analysis of the fibre volume fraction, the behaviour of the profile in figure 11 indicated a gradual increase in impact energy as the fibre volume fraction increased. This is to say that, considering the specimens used in this investigation, as the sudden impact force was applied, there was a rise in resistance as fibre volume fraction increased, but, later on, the deviation from what appears to be cons- 
tant volume fraction line was minimal with in continuous increased in impact strength. This suggests that there exists a fibre volume fraction at which laminate possesses ultimate impact strength (figure 10).

\section{CONCLUSIONS}

Fibre volume fraction and impact strength analysis of reinforced polyester composites had been achieved. In this study, the thickness of the developed reinforced polyester specimens were varied using the fibre volume fraction. The effects of specimen thickness and fibre volume fraction on impact responses and fracture mechanism for each developed composite were investigated. The results obtained shows that the effective thickness of the developed reinforced composites ranges from $60 \mathrm{~mm}$ to $100 \mathrm{~mm}$ at fibre fraction which ranges from 0.32 to 0.50 . The results obtained also shows that the specimens containing woven roving have greater resistance to fracture and impact damages due to high fibre volume fraction. Hence, the laminates impact strength is a function of its fibre volume fraction. The results obtained also shows that the thicker specimens based on the presence of woven roving reinforcement the greater the impact resistance to delamination and crack propagation for the same impact area. In other words, for identical sudden impact force, the damage and fracture areas of the thicker plates were much smaller than those of the thin plates.

\section{Conflicts of Interest}

There is no conflict of interest in this research article.

\section{REFERENCES}

[1] Osaretin, M.O. and Olodu, D.D. (2021). Stress Mechanics of Reinforced Polyester Composites. International Journal of Engineering and Innovative Research, 3(1): 39-54

[2] Ladeveze, P. and Le Dantec, E. (1992). Damage Modelling of the Elementary Ply for Laminated Composites. Composite Science and Technology Journal, 43: 257-267.

[3] Kao, W. S. (2003). Fracture Toughness of a Laminated Composite. Fracture of Polymers, Composites and Adhesives II, Elsevier, 355-364

[4] Mueller, D. H. and Krobjilowski, A. (2004). Improving the Impact Strength of Natural Fibre Reinforced Composites By Specifically Designed Materials and Process Parameter. International Nonwovens Journal, 13(4): 31-38.

[5] Silva, J. F., Vieira, P., Morais, A. B., Marques, A. T. and De Castro, P. M. S. T. (2007). Mode-II Fracture Toughness of Glass Reinfored Composites. Universidade de Aveiro, Campus Santiago, Aveiro, Portugal, 38-50.

[6] Williams, J. G. (1978). Linear Fracture Mechanics. Advances in Polymer Science, Springer Varlag, Berlin, Heidelberg, New York, 27: 69 $-82$.

[7] Parhizgar, S., Zachary, L. W. and Sun, C. T. (1982). Application of the Principle of Linear Fracture Mechanics to the Composite Materials. International Journal of Fracture Mechanics, 20: 3-15.

[8] Mandel, J. A., Pack, S. C. and Tarazi, S. (1982). Micromechanical Studies of Crack Growth in Fibre Reinforced Materials. Engineering Fracture Mechanics, 16: 741-754.
[9] Garo, A. C. and Trotman C. K. (1980). Effect of Water on Fracture Toughness of Reinforced Composites. Engineering Fracture Mechanics Journal, 24(2): 34-45

[10] Radif, Z. S. and Ali, A. (2001). Fracture Toughness of Kenaf Mat Reinforced Polyester Composite. Pertanika Journal of Science and Technology, 99(1): 177-187.

[11] Idicula, M., Joseph, K. and Thomas, S. (2009). Mechanical Performance of Short Banana/Sisal Hybrid Fibre Polyester Composite. Journal of Reinforced Plastics and Composites, 29(1): 12 - 29

[12] Liu, Q., Hughes, M. (2008). The Fracture Behaviour and Toughness of Woven Flax Fibre reinforced epoxy Composites. Composites Part A: Applied Science and Manufacturing, 8(4): 23-30. 